Special Issue of the 8th International Advances in Applied Physics and Materials Science Congress (APMAS 2018)

\title{
Energy Recovery Analysis in A-Type Pressure Regulation and Measurement Stations in Istanbul, Esenyurt
}

\author{
M. Atmaca ${ }^{a, *}$, Y. Uraltaş ${ }^{a}, \mathrm{~A} . \mathrm{OnAT}^{a}$ And C. Ezgi ${ }^{b}$ \\ ${ }^{a}$ Marmara University, Mechanical Engineering Department, Istanbul, Turkey \\ ${ }^{b}$ Beykent University, Mechanical Engineering Department, Istanbul, Turkey
}

\begin{abstract}
Converting energy sources into electrical energy is as important as gaining energy. After producing natural gas, which is one of the most common energy sources and classified as fossil fuel, it is sold by the natural gas and petrol companies to the world by compressing it in the compressor stations. Gas companies compress incoming gas which is lost in the pipeline into 35-75 bar equal to the loss rate and transfer it to the A-type pressure regulation measurement stations. In these stations, natural gas that enters with high pressure is reduced to 12-19 bar by throttle valve. This process happens using the Joule-Thomson effect. Hence, no energy is produced in this process. There is a big waste of producible electrical energy in this situation. In this work, turboexpander which is suitable for radial type variant flow has been considered to be used instead of throttle valve at the stations. In this work, A-type pressure regulation measurement station in Esenyurt yearly gas values, inlet and outlet gas pressure values, inlet and outlet temperature values were searched and gained electric energy value was searched in case of installing turboexpander to this station.
\end{abstract}

DOI: 10.12693/APhysPolA.135.622

PACS/topics: pressure regulation measurement station (RMS), turbine, energy, efficiency

\section{Introduction}

Energy requirement of human civilization has existed and continued since the existence process itself. Resources above and under the ground have been utilized in order to meet energy requirements. Efficient utilization of energy obtained from resources above and under the ground is as significant as production of energy. Energy saving is the most important factor in terms of energy efficiency. Saving on energy actually denotes decrease in energy consumption amount by utilization of energy wastes as well as prevention of existing energy losses. The issue of energy efficiency comprises methods including prevention of energy losses of heat, gas, steam, air, and electricity, recovery and utilization of various types of wastes or decrease in energy demand without lowering the production value, which have been possible due to advanced technology and energy recovery $[1,2]$.

One of the methods of ensuring energy efficiency is producing electric energy through usage of turboexpander instead of expansion valve which does not produce work due to the Joule-Thomson effect in natural gas pressure reducing stations $[3,6]$. The results obtained when turboexpander is placed instead of expansion valves which are employed as a standard in A-type pressure reducing station have been researched in this study. Various similar studies can be found in this regard in the literature. Mirandola and Minca [7] have determined design criteria by taking into account thermodynamic conditions as regarding power generation from high pressure natural gas,

*corresponding author; e-mail: matmaca@marmara.edu.tr gas withdrawal amounts, pressure reduction phases, as well as preheating requirements. They suggested design conditions for 8 plants in Italy. The number of stages varied from 1-3, while the inlet pressures ranged from 51-11.3 bar, and outlet pressure ranged from 6-1.5 bar. It was shown that the specific production of electrical energy could be $0.028-0.0644 \mathrm{kWh} /\left(\mathrm{N} \mathrm{m}^{3}\right)$ of gas. With design flow rates ranging from $5000-30000 \mathrm{~N} \mathrm{~m}^{3} / \mathrm{h}$, resulting power output varied from $300-1400 \mathrm{kWh}$. In a subsequent paper, Mirandola and Macor [8] presented experimental results and analysis of real data from a prototype plant built in 1987 in Ravenna, Italy. At initial stages the plant showed some operational problems which were rectified later. In two separate periods totalling 84 days, it produced $971 \mathrm{MWh}$ of electricity. Poživil reported simulation results for a gas transmission station at Velké Němčice, Czech Republic [9]. It is mentioned that temperature drop in the throttle valve can be about $0.45-$ $0.6^{\circ} \mathrm{C}$ per bar of pressure drop, whereas with turboexpanders it can be much higher, around $1.5-2{ }^{\circ} \mathrm{C}$ per bar, depending on the gas composition.

\section{Material and methods}

Instant gas flow, instant temperature changes as well as instant pressure values within the year, were provided by virtue of turbine meter, ultrasonic meter, pressure, and temperature meter equipments currently operating in RMS-A, Regulation and Measurement Station (Esenyurt District A-type Pressure Reducing Station) in addition to obtaining components of the gas through utilization of gas chromatography device in this study. In the light of this data, energy recovery analysis in case of placing turboexpander instead of expansion valve Esenyurt District RMS-A located in İstanbul province, was 
conducted through utilization of the process simulation program named HYSYS which is especially used in the energy sector and the theoretical calculation method in order to confirm foregoing. Expansion has been calculated by virtue of Eqs. (1)-(6), taking into account the power generation to turbine, gas consumption to take place at preheating, required turbine inlet temperature, work performed, and total electricity production.

\section{Results and discussion}

According to January data in Esenyurt RMS-A station: gas inlet pressure $P_{1}=45.78$ bar, turbine inlet pressure $P_{2}=45.78 \mathrm{bar}$, average gas flow $Q=$ $423.618 \mathrm{~S} \mathrm{~m}^{3} / \mathrm{h}$, gas inlet temperature $T_{1}=13.39{ }^{\circ} \mathrm{C}$, gas outlet temperature $T_{3}=12.58^{\circ} \mathrm{C}$, turbine outlet pressure $P_{3}=21.55$ bar, average higher heat value (HHV) for natural gas $=9347.2734 \mathrm{kcal} /\left(\mathrm{S} \mathrm{m}^{3}\right)$, turbine adiabatic efficiency $=78 \%$ (assumed), gear box and generator efficency $=90 \%$ (assumed), density of natural gas $(\rho)=0.7163 \mathrm{~kg} / \mathrm{m}^{3}\left(15^{\circ} \mathrm{C}\right.$ and 1.01325 bar $)$. The turbine efficiency $\left(\eta_{T}\right)$ is calculated as follows:

$$
\eta T=\frac{h_{2}-h_{3}}{h_{2}-h_{3 s}} .
$$

$s_{2}=s_{3 s} \mathrm{~kJ} /(\mathrm{kg} \mathrm{K})$ (isentropic process). For $P_{1}=$ 45.78 bar and $T_{1}=13.39^{\circ} \mathrm{C}$, from diagram (pressureenthalpy diagram for methane), $h_{1}$ and $s_{1}$ are found as follows: $h_{1}=-75 \mathrm{~kJ} / \mathrm{kg}, s_{1}=-2.18 \mathrm{~kJ} /(\mathrm{kg} \mathrm{K})$, $P_{2}=45.78$ bar, $T_{2}=56{ }^{\circ} \mathrm{C}$ (turbine inlet temperature $T_{2}$ is assumed as $56^{\circ} \mathrm{C}$ for $78 \%$ turbine efficiency). For $P_{2}=$ 45.78 bar and $T_{2}=56^{\circ} \mathrm{C}$, from diagram, $h_{2}$ and $s_{2}$ are found as follows: $h_{2}=40 \mathrm{~kJ} / \mathrm{kg}, s_{2}=-1.81 \mathrm{~kJ} /(\mathrm{kg} \mathrm{K})$. For $P_{3}=21.55$ bar and $T_{2}=12.58^{\circ} \mathrm{C}$, from diagram, $h_{3}$ and $s_{3}$ are found as follows: $h_{3}=-52 \mathrm{~kJ} / \mathrm{kg}, s_{3}=$ $-1.66 \mathrm{~kJ} /(\mathrm{kg} \mathrm{K})$. At this point, $P_{3 s}=P_{3}=21.55$ bar. If $s_{2}=s_{3 s}$ is assumed as isentropic, from diagram (pressure-enthalpy diagram for methane), $T_{3 s}$ and $s_{3 s}$ are found as follows: $T_{3 s}=-1{ }^{\circ} \mathrm{C}, s_{3 s}=-1.81 \mathrm{~kJ} /(\mathrm{kg} \mathrm{K})$ and $h_{3 s}=-78 \mathrm{~kJ} / \mathrm{kg}$. If the enthalpy values are written in Eq. (1), turbine adiabatic efficiency $n_{T}$ is found as follows:

$n_{T} \cong 77.96$ (as found). Total amount of preheating gas consumption $\left(Q_{\text {cons }}\right)$ are calculated as follows:

$$
\begin{aligned}
& Q_{\text {cons }}=\dot{Q} / \mathrm{HHV}, \\
& \dot{Q}=\dot{m} c_{p}\left(T_{2}-T_{1}\right) / 4.18 \mathrm{kcal} / \mathrm{h}, \\
& \dot{m}=\rho Q,
\end{aligned}
$$

where $Q$ is average gas flow for January, $\dot{m}=0.7163 \times$ $423618=303437.5734 \mathrm{~kg} / \mathrm{h}, \dot{Q}=303437.5734 \times 2.18 \times$ $(56-13.39) / 4.18$ is $\dot{Q}=6743123.32 \mathrm{kcal} / \mathrm{h}$.

Accordingly, $Q_{\text {cons }}=6743123.32 / 9347.2734, Q_{\mathrm{cons}}=$ $721.4 \mathrm{~S} \mathrm{~m}^{3} / \mathrm{h}$. Total power in turbine

$$
\begin{aligned}
& \dot{W}=\dot{m} c_{p} \times\left(T_{2}-T_{3}\right) / 3600 \mathrm{~kW} \\
& \dot{W}=303437.5734 \times 2.18 \times(56-12.58) / 3600=
\end{aligned}
$$

$$
7978.35 \mathrm{~kW} \text {. }
$$

If the gearbox and generator efficiency is assumed as $90 \%$, net power $\left(\dot{W}_{\text {net }}\right)$ is found as follows:

$$
\begin{aligned}
& \dot{W}_{\text {net }}=0.9 \dot{W}, \\
& \dot{W}_{\text {net }}=7978.355 \times 0.9=7180.51 \mathrm{~kW} .
\end{aligned}
$$

In this study, an energy recovery analysis was implemented in case the expansion turbine was replaced with the expansion valve in the RMS-A in Esenyurt, Istanbul. This analysis was carried out using the simulation program HYSYS used in the energy sector. The heat exchanger and the turboexpander were defined in the program. Subsequently, chromatographic structure of the gas entering the system was defined, and then PengRobinson model was chosen as the analysis method. Afterwards boiler hot water inlet temperature for turboexpander, gas inlet flow, gas inlet and outlet pressure, gas inlet and outlet temperature, and turbine adiabatic efficiency were defined.

Composition of gas as a percentage for Esenyurt BDIA station: methane $=0.932$, ethane $=0.046$, propane $=$ 0.0105, i-butane $=0.0018$, n-butane $=0.00180$, i-Pentane $=0.000418$, n-pentane $=0.000310$, nitrogen $=0.00395$, $\mathrm{CO}_{2}=0.00154, \mathrm{H}_{2} \mathrm{O}=0$, n-Hexane $=0.00023$.

The turbine inlet temperature was observed to be $56^{\circ} \mathrm{C}$ by virtue of the HYSYS program. It was observed that this input temperature value, which was found by looking at the $P-h$ diagram for methane gas, is compatible with the temperature value obtained through the program.

Monthly electricity production values of the Esenyurt District Pressure Reducing Station and the required turbine inlet temperature values are shown in Table I. Potential electricity generation of the turbine is realized as $7978 \mathrm{kWh}$ in the light of current data. The total generated electricity energy was calculated as $7180 \mathrm{kWh}$ based on the assumption that the gearbox and generator efficiency is $90 \%$. Electricity production was found to be linear with the amount of gas flow as it can be seen in Table I. When the gas flow reached $423618 \mathrm{~S} \mathrm{~m}^{3} / \mathrm{h}$, the electricity generated became $7180 \mathrm{kWh}$. The lowest electricity production occurred in July when the gas flow was $125464 \mathrm{~S} \mathrm{~m}^{3} / \mathrm{h}$ and the electricity production amount became $2837 \mathrm{kWh}$. It is observed that increase in $P_{1} / P_{2}$ rate causes an increase in potential electricity generation of the turbine. The average amount of electricity generation during the year was calculated as $5270 \mathrm{kWh}$.

In Fig. 1 the amount of preheating gas consumption depending on the gas flow is shown for those two months of the year. When Fig. 1 is examined, it is seen that as the flow of gas passing through the turboexpander increases, the preheating gas requirement also increases. At the RMS-A in Esenyurt District, when the gas flow rate reached $429626 \mathrm{~S} \mathrm{~m}^{3} / \mathrm{h}$, the flow of the gas spent for preheating was $721 \mathrm{~S} \mathrm{~m}^{3} / \mathrm{h}$. The lowest gas consumption was realized as $250 \mathrm{~S} \mathrm{~m}^{3} / \mathrm{h}$ in July when the gas flow rate was $125464 \mathrm{~S} \mathrm{~m}^{3} / \mathrm{h}$. When preheating is made in the expansion valve, the consumption of gas is $231 \mathrm{~S} \mathrm{~m}^{3} / \mathrm{h}$ for January. As this is an 
Esenyurt A type regulation and measurement station producing electricity

\begin{tabular}{l|c|c|c|c|c|c|c|c}
\hline \hline \multicolumn{1}{c|}{ Month } & $\begin{array}{c}\text { Flow } \\
{\left[\mathrm{S} \mathrm{m}^{3} / \mathrm{h}\right]}\end{array}$ & $\begin{array}{c}\text { Energy } \\
{[\mathrm{kWh}]}\end{array}$ & $P_{1} / P_{2}$ & $\begin{array}{c}\text { Inlet } \\
\text { pres. [bar] }\end{array}$ & $\begin{array}{c}\text { Outlet } \\
\text { pres. [bar] }]\end{array}$ & $\begin{array}{c}\text { Inlet } \\
\text { temp. }\left[{ }^{\circ} \mathrm{C}\right]\end{array}$ & $\begin{array}{c}\text { Turbine inlet } \\
\text { temp. }\left[{ }^{\circ} \mathrm{C}\right]\end{array}$ & $\begin{array}{c}\text { Turbine outlet } \\
\text { temp. }\left[{ }^{\circ} \mathrm{C}\right]\end{array}$ \\
\hline January & 423618 & 7180 & 2.1 & 45.78 & 21.55 & 13.3 & 56.00 & 12.37 \\
February & 349541 & 6692 & 2.4 & 53.91 & 22.48 & 13.6 & 60.00 & 10.56 \\
March & 389526 & 7588 & 2.4 & 53.62 & 22.02 & 14.0 & 62.00 & 11.72 \\
April & 251725 & 5188 & 2.5 & 55.87 & 21.83 & 14.6 & 65.00 & 11.78 \\
May & 213374 & 4655 & 2.8 & 58.30 & 20.47 & 15.7 & 68.00 & 11.67 \\
June & 155707 & 3547 & 2.8 & 58.01 & 20.54 & 17.5 & 70.00 & 11.17 \\
July & 125464 & 2837 & 2.8 & 58.47 & 20.40 & 19.3 & 70.00 & 11.61 \\
August & 144715 & 3448 & 3.0 & 60.00 & 20.05 & 20.9 & 73.00 & 11.47 \\
September & 138244 & 3405 & 3.0 & 60.00 & 20.42 & 21.5 & 75.00 & 11.39 \\
October & 263562 & 5645 & 2.6 & 58.36 & 22.06 & 20.9 & 60.00 & 12.69 \\
November & 429626 & 7191 & 2.2 & 49.89 & 22.38 & 19.0 & 55.00 & 11.78 \\
December & 366302 & 5894 & 2.1 & 47.03 & 22.29 & 15.2 & 53.00 & 11.45 \\
annual average & 270950 & 5270 & 2.6 & 55.30 & 21.37 & 17.1 & 64.58 & 11.64
\end{tabular}

isentropic process, pressure decreases in the turboexpander while enthalpy changes, and therefore work is produced between inlet and outlet point. Temperature decreases more in the turboexpander compared to the expansion valve, because pressure decrease occurs between the range of $1.5^{\circ} \mathrm{C}$ and $2{ }^{\circ} \mathrm{C} / \mathrm{bar}$, so it is seen that more preheating is involved to the preheating process in order to achieve the desired output temperature. Consumption of preheating gas was $721 \mathrm{~S} \mathrm{~m}^{3} / \mathrm{h}$ for January. As a result, the turboexpander has been found to have almost four times more preheating gas consumption compared to the expansion valve during the year. The amount of electricity production of the turboexpander system depending on the gas flow during twelve months is shown in a comparative way in Fig. 2. It was observed that the electricity production was parallel to the amount of gas flow and when the gas flow reached $429626 \mathrm{~S} \mathrm{~m}^{3} / \mathrm{h}$ the amount of electricity generated became $7180 \mathrm{kWh}$. The lowest electricity generation was realized in July when the gas flow was $125464 \mathrm{~S} \mathrm{~m}^{3} / \mathrm{h}$. In July, electricity production was realized as $2837 \mathrm{kWh}$.

The electricity production values for twelve months starting from the first month of the turboexpander at $78 \%, 82 \%$, and $86 \%$ efficiencies is shown in a comparative way in Fig. 3. At each level of efficiency increase, the turbine-produced electrical generation increased linearly as can be seen in Fig. 3. Furthermore, it was determined that increase in electricity production between $168 \mathrm{kWh}$ and $585 \mathrm{kWh}$ took place at each four-point efficiency increase. Turbine inlet temperatures starting from the first month at $78 \%, 82 \%, 86 \%$ efficiencies of turboexpander were provided in a comparative way. Turbine inlet temperature was observed to increase linearly at each level of efficiency increase. Furthermore, it was observed that preheating temperature increased between $1{ }^{\circ} \mathrm{C}$ and $6{ }^{\circ} \mathrm{C}$ at each four-point efficiency increase. Turbine preheating gas consumption comparison was made starting from the first month at $78 \%, 82 \%$, and $86 \%$ efficiencies of the turboexpander, respectively. It was observed that preheating gas consumption increased between $20 \mathrm{~S} \mathrm{~m}^{3} / \mathrm{h}$ and $84 \mathrm{~S} \mathrm{~m}^{3} / \mathrm{h}$ at each four-point efficiency increase.

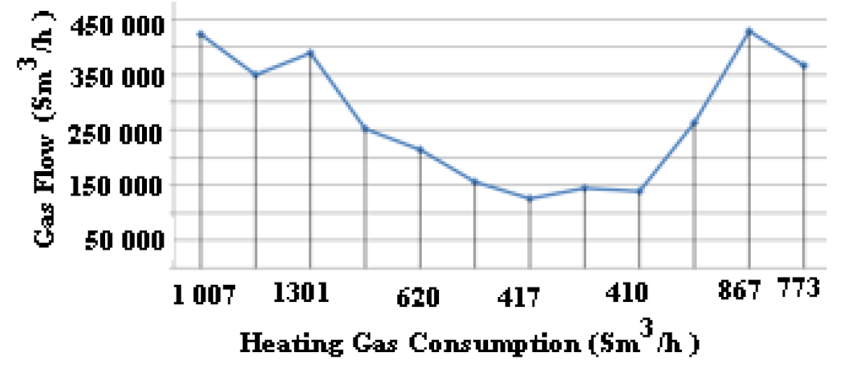

Fig. 1. Gas flow - pre-heating gas consumption.

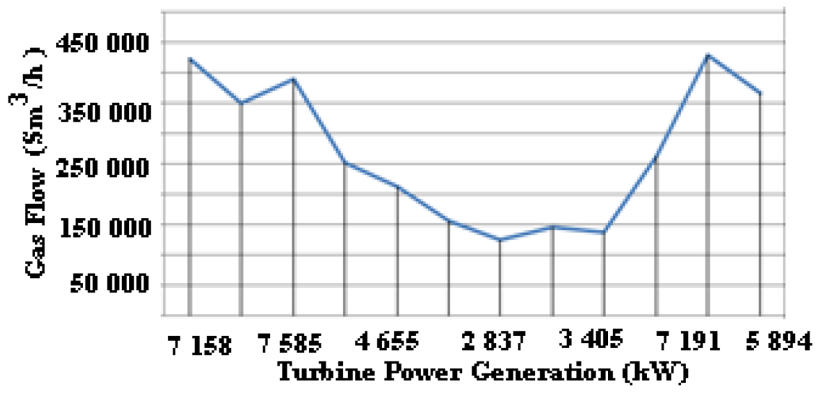

Fig. 2. Flow and total produce electricity in turboexpander.

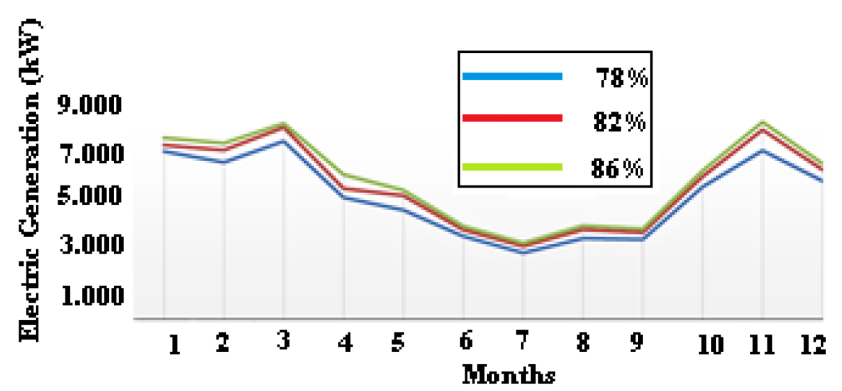

Fig. 3. Expansion turbine efficiency-electricity generation. 


\section{Conclusions}

Turboexpander application was made for Esenyurt District A-type Pressure Reducing Station (RMS-A) in this study. Electricity generation value of Esenyurt District RMS-A station, distribution of electricity production value during the year, the value of gas withdrawal within the year, and gas consumption values spent for preheating were found in this context. It was observed that when the turboexpander system was utilized instead of the expansion valve, decrease in pressure between $1.5^{\circ} \mathrm{C} /$ bar and $2{ }^{\circ} \mathrm{C} /$ bar took place. It was calculated that there was almost four times more gas consumption in preheating compared to expansion valve so that the gas could reach the required pressure and temperature values at the outlet. It was observed that gas consumption and turbine efficiency changed in direct proportion. It was also observed that at each four-point efficiency increase there was gas consumption increase between $20 \mathrm{~S} \mathrm{~m}^{3} / \mathrm{h}$ and $84 \mathrm{~S} \mathrm{~m}^{3} / \mathrm{h}$ and at each four-point efficiency increase there was preheating temperature increase between $1{ }^{\circ} \mathrm{C}$ and $6{ }^{\circ} \mathrm{C}$. It was determined that increase in $P_{1} / P_{2}$ ratio caused increase in the turbine's potential electricity production. It is expected that an average of $5270 \mathrm{kWh}$ of electricity will be generated annually if this system is installed. It was determined that electricity production increased linearly in line with the increase of the inlet gas flow. As a result, if a turboexpander is utilized instead of the expansion valve, a substantial amount of wasted energy will be recovered. Furthermore, it is expected to provide contribution to decrease in greenhouse gas emission values with the utilization of the existing wasted energy.

\section{References}

[1] C. Akyol, RMS-A Regulation and Measuring Station, Istanbul 2015.

[2] Ö. Deniz, M.Sc. Thesis, İstanbul Technical University, Institute of Science and Technology, İstanbul 2014.

[3] G. Bisio, Energy 20, 161 (1995).

[4] H.P. Bloch, C. Soares, Turboexpanders and Process Applications, Butterworth, Stoneham (MA) 2015.

[5] W.G. Kortekaas, C.J. Peters, J.D.S. Arons, Fluid Phase Equilibr. 139, 205 (1997).

[6] I. Andrei, T. Valentin, T. Cristina, T. Niculae, Proced. Eng. 69, 986 (2014).

[7] A. Mirandola, L. Minca, in: Proc. 21st Intersociety Energy Conversion Engineering Conf., San Diego (California) 1986, Vol. 1, p. 16.

[8] A. Mirandola, A. Macor, in: Proc. 23rd Intersociety Energy Conversion Engineering Conf., Colorado 1988, Vol. 4, p. 33.

[9] J. Poživil, Acta Montanist. Slov. 9, 258 (2004). 